\title{
Introduction to Tractate Hagigah
}

As their name indicates, the holidays of pilgrimage trigger two obligations: to appear in the Temple as pilgrims, and to observe the holiday as time of happiness. Since also one may not appear in the Temple empty-handed (Ex. 23:14) the pilgrim has to bring two sacrifices: an elevation sacrifice to celebrate his entry to the Temple with a gift, and a wellbeing sacrifice to provide the meal for the family celebration of the holiday. The Tractate contains the rules of both sacrifices together with many connected subjects. The First Chapter details the rules of the pilgrimage and its sacrifices. Since the holiday obligations may be satisfied only on a holiday, this leads to examples of what in Proverbs is described as what is crooked cannot be made straight. This again leads to a list of traditional rules with little, or no biblical background. The Second Chapter starts with a list of topics unfit for public treatment, followed by a discussion of the disagreement between Pharisaic schools about the handling of the required sacrifices on the holiday proper, including the special rules for the one-day holiday of Pentecost. The end of the Chapter, and the entirety of Chapter Three, are devoted to the levels of purity required for profane food, non-Temple sancta, and Temple sancta, together with the special holiday rules enacted to include all of Israel in the celebrations with no regard to the level of observation of the rules of purity particular to the individual celebrant. 